DT $\# 44995$

\title{
Gamma-Ray Characterization of the U-Series Intermediate Daughters from Soil Samples at the Peña Blanca Natural Analog, Chihuahwa, Mexico
}

\author{
Diana C. French, Elizabeth Y. Anthony, and Philip C. Goodell (UTEP)
}

The Peria Blanca natural analog is located in the Sierra Pena Blanca, approximately 50 miles north of Chihuahua City, Mexico. The Sierra Peña Blanca is composed mainly of ash-flow tuffs, and the uranium in the region is contained in the brecciated zones of these tuffs. The Peña Blanca site is considered a natural analog to the proposed Yucca Mountain Nuclear Waste Repository because they share similar characteristics of structure, volcanic lithology, tectonic activity, and hydrologic regime. One of the mineralized zones, the Nopal I deposit, was mined in the early 1980 s and the ore was stockpiled close to the mine. This stockpile area has subsequently been cleared and is referred to as the prior high-grade stockpile (PHGS) site.

Soil surrounding boulders of high-grade ore associated with the PHGS site have been sampled. The purpose of this study is to characterize the transport of uranium series radioisotopes from the boulder to the soil during the past 25 years. Transport is characterized by determining the activities of individual radionuclides and daughter to parent ratios. The daughter to parent ratios are used to establish whether the samples are in secular equilibrium. Activities are determined using gamma-ray spectroscopy. Isotopes of the uranium series decay chain detected by gamma-ray spectroscopy include ${ }^{210} \mathrm{~Pb}$, ${ }^{234} \mathrm{U},{ }^{234} \mathrm{Th}^{230} \mathrm{Th},{ }^{226} \mathrm{Ra},{ }^{214} \mathrm{~Pb},{ }^{214} \mathrm{Bi}$, and ${ }^{234} \mathrm{~Pa}$. Preliminary results indicate that some daughter to parent pairs appear to be in secular disequilibrium. Thorium is in excess relative to uranium, and radium is in excess relative to thorium. A deficiency appears to exist for ${ }^{210} \mathrm{~Pb}$ relative to ${ }^{214} \mathrm{Bi}$ and ${ }^{214} \mathrm{~Pb}$. If these results are borme out by fiurther analysis, they would suggest transport of nuclides from the high-grade boulder into its surroundings, followed by continued leaching of uranium and lead from the environment. 